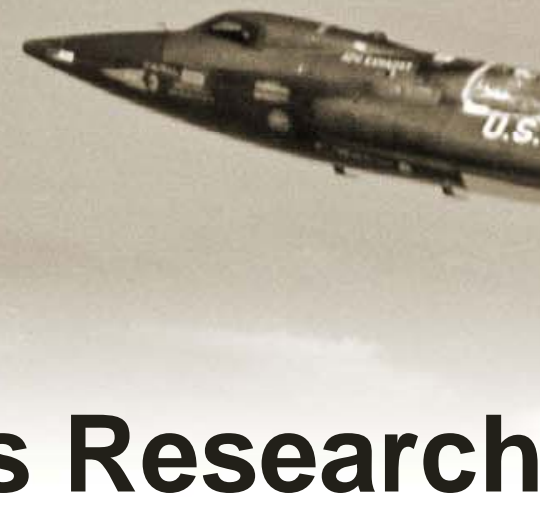

\title{
NASA Aeronautics Research
}

\section{Dr. Jaiwon Shin}

Associate Administrator

Aeronautics Research Mission Directorate

\section{AIAA Conference} January 4, 2011

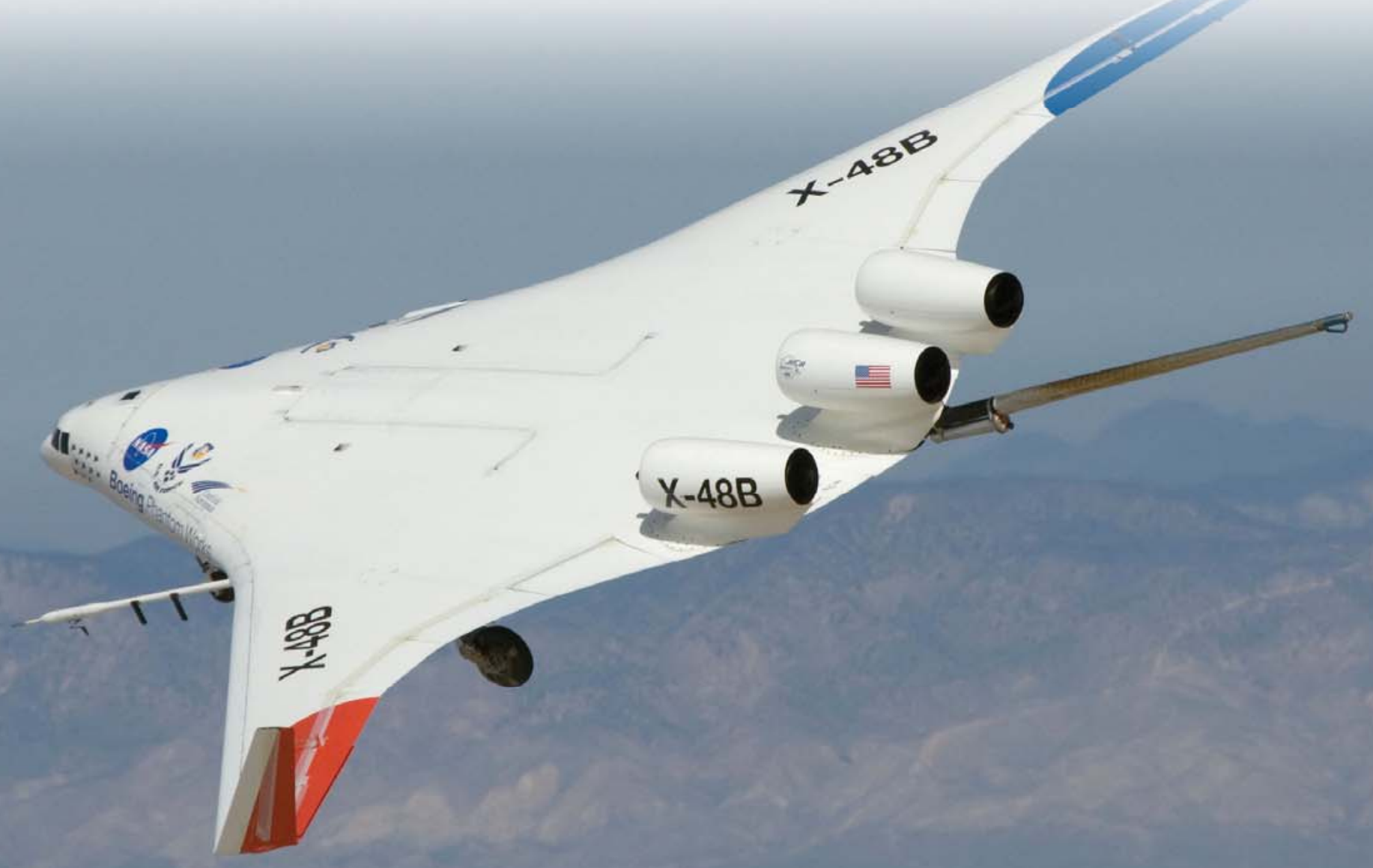




\section{Why Aeronautics R\&D is Important}

- $\$ 436$ billion in direct economic activity

- Provides \$60.6B positive trade balance

- $25 \%$ of all companies' sales depend on air transportation

- 655,500 jobs

- 650 million travelers a year
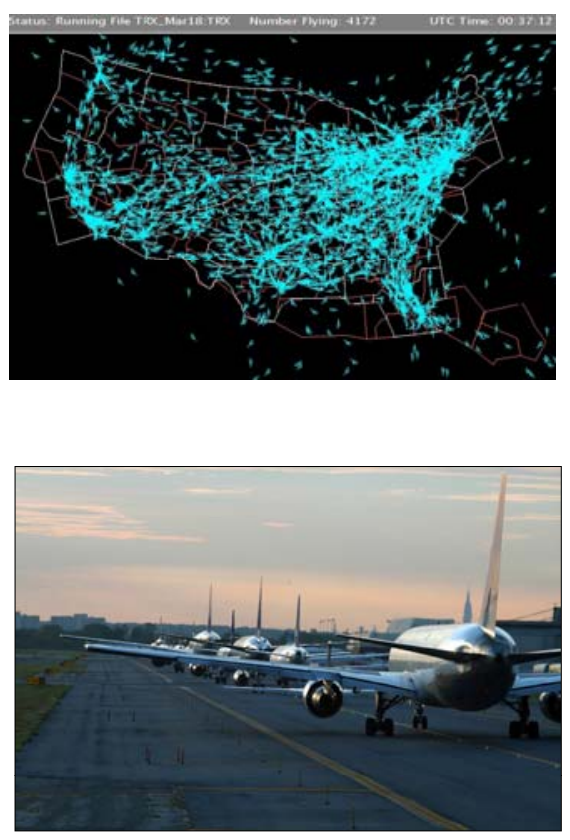

- 51,000 flights a day

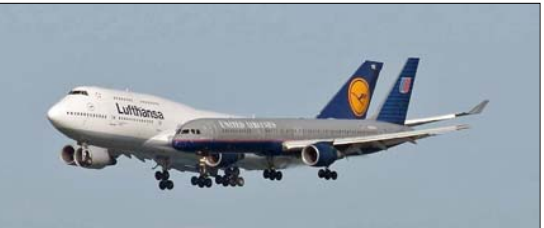




\section{National Calls for Aeronautics R\&D}

National Aeronautics Research and Development Policy

Executive Order signed by President Bush December 2006

National Plan for Aeronautics Research and Development and Related Infrastructure

Original plan signed by White House December 2007;

Biennial update signed Feb 2010

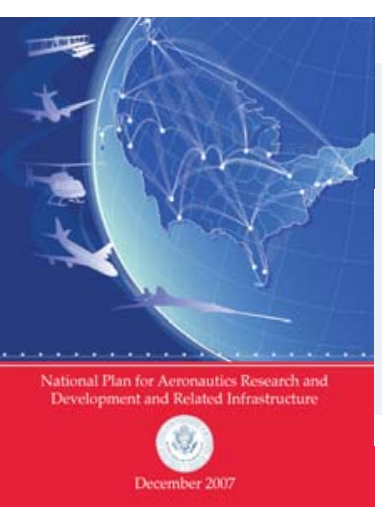

\section{NextGen}

Vision100: Public Law 108-176, December 2003
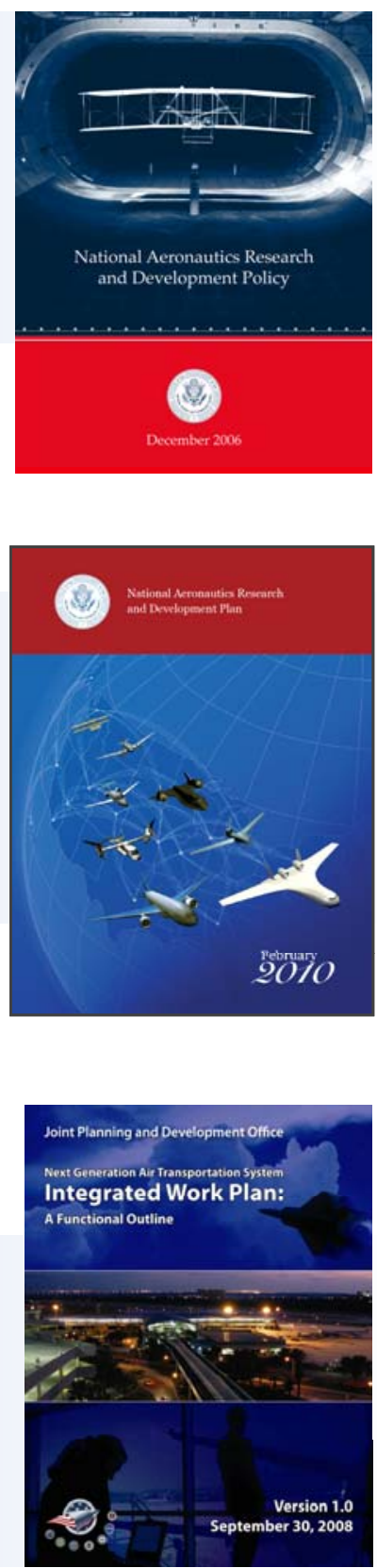

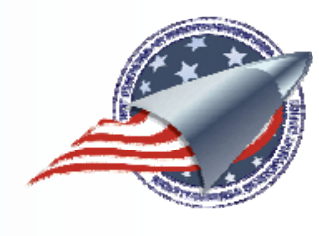




\section{NASA Aeronautics Investment Strategy}

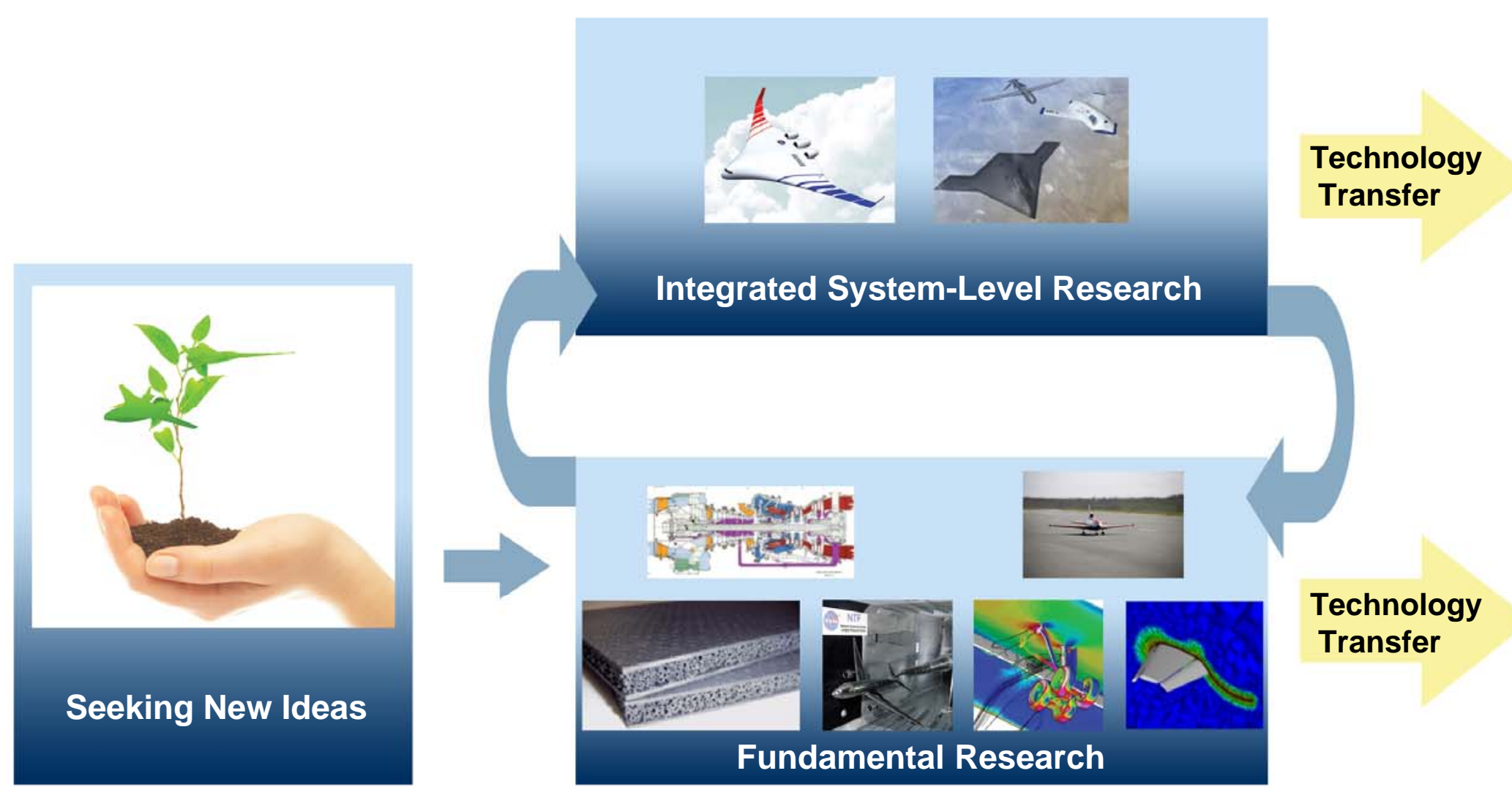

Enabling "Game Changing" concepts and technologies from advancing fundamental research ultimately to understand the feasibility of advanced systems 


\section{NASA Aeronautics Programs in FY2011}

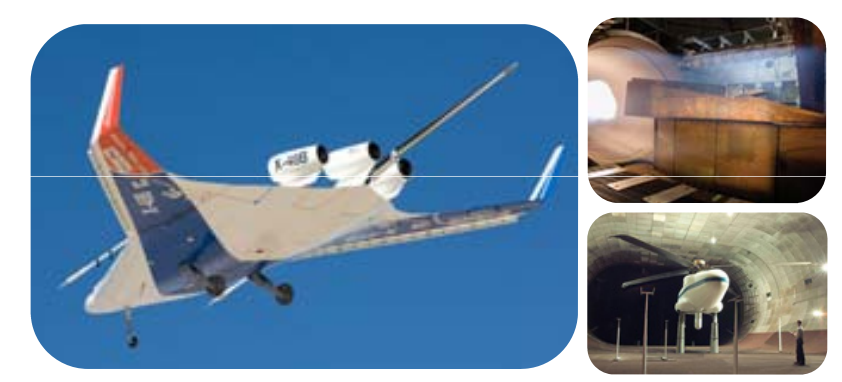

\section{Fundamental Aeronautics Program}

Conduct cutting-edge research that will produce innovative concepts, tools, and technologies to enable revolutionary changes for vehicles that fly in all speed regimes.

\section{Integrated \\ Systems \\ Research Program}

Conduct research at an integrated system-level on promising concepts and technologies and explore/assess/demonstrate the benefits in a relevant environment
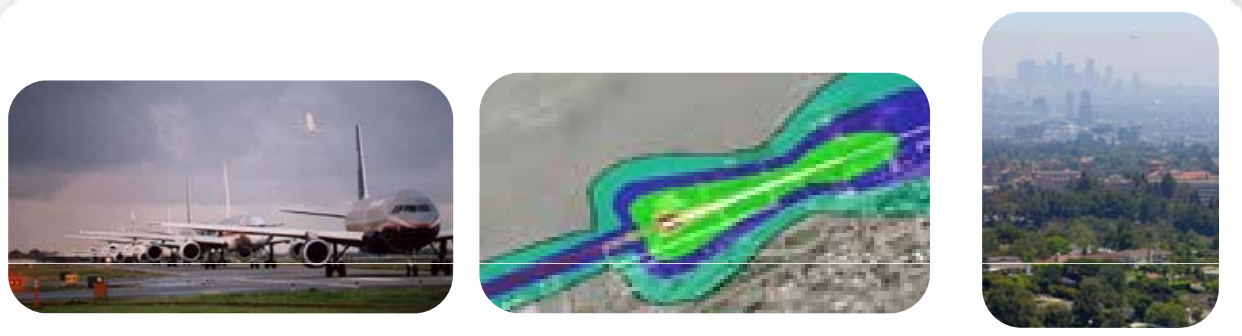
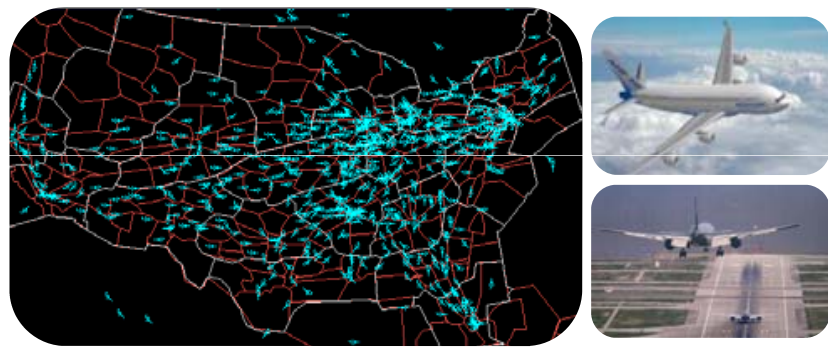

Airspace Systems Program

Directly address the fundamental ATM research needs for NextGen by developing revolutionary concepts, capabilities, and technologies that will enable significant increases in the capacity, efficiency and flexibility of the NAS.
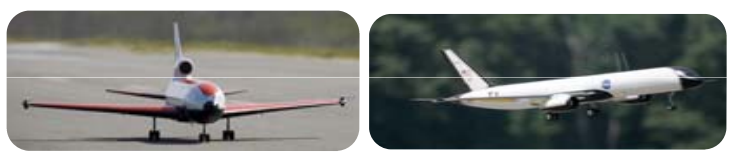

\section{Aviation Safety Program}

Conduct cutting-edge research that will produce innovative concepts, tools, and technologies to improve the intrinsic safety attributes of current and future aircraft.
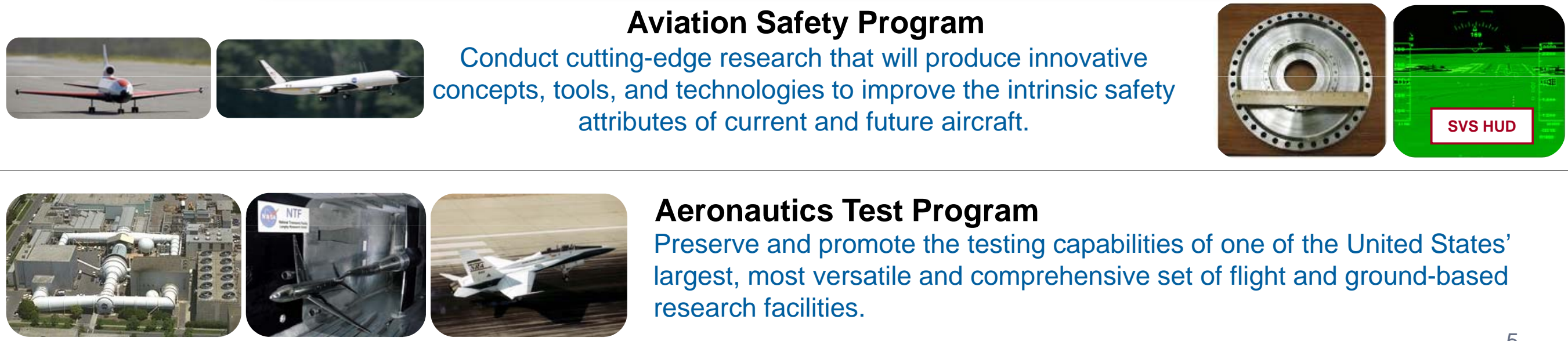

\section{Aeronautics Test Program}

Preserve and promote the testing capabilities of one of the United States' largest, most versatile and comprehensive set of flight and ground-based research facilities. 


\section{NASA Aeronautics Budget for FY2007-FY2015 NAsA}

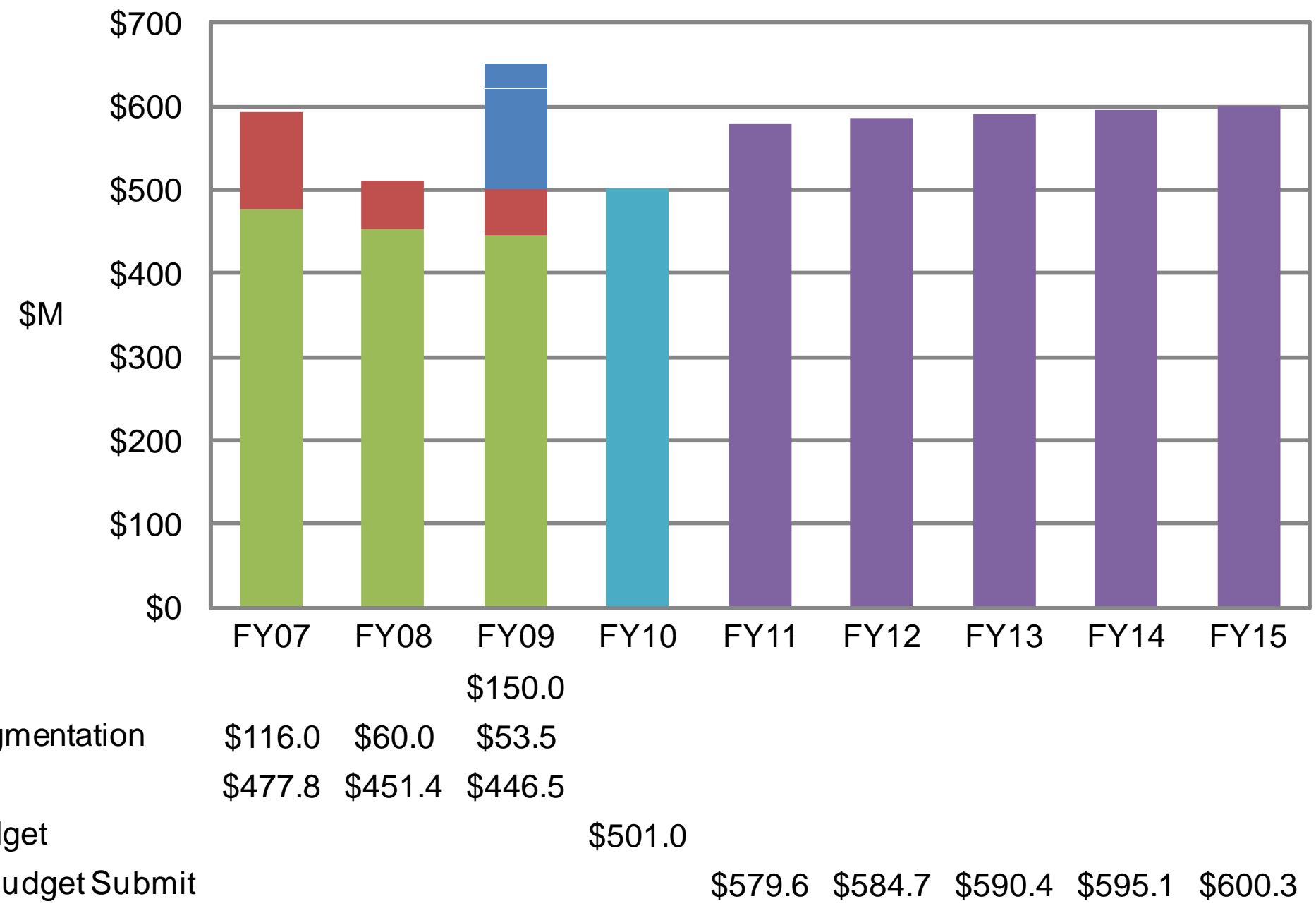

Note: The budget request columns for FY07 and FY08 have been adjusted from the initial request to reflect full cost simplification. The FY09 budget request column is from the FY09 President's Budget. The FY10 budget column is the enacted budget for this year. 


\section{FY2010 Accomplishments}

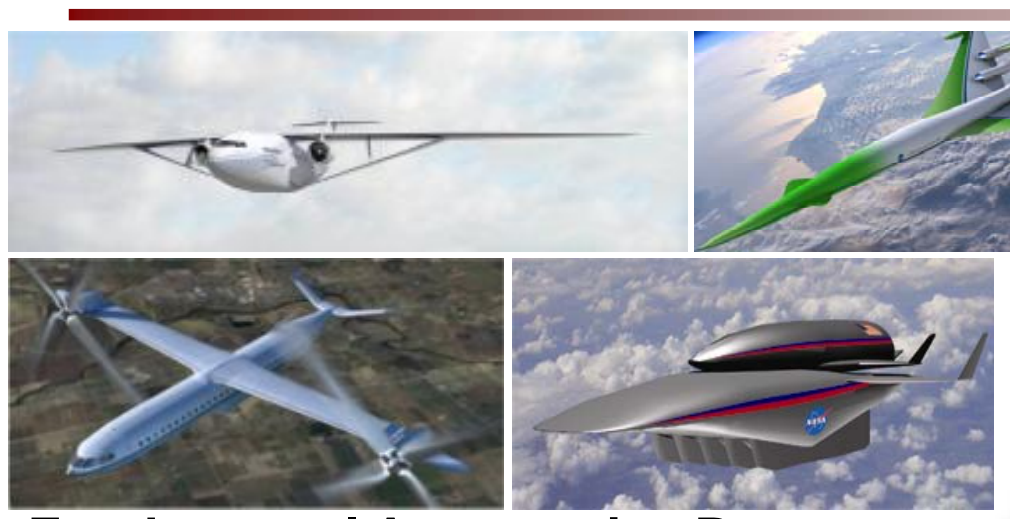

\section{Fundamental Aeronautics Program}

- N+3 advanced concept studies of 2035 subsonic \& supersonic aircraft provide guidance for future NASA technology development

- Successful full-scale helicopter rotor test resulted in complete set of advanced code validation data

- Significant progress in validating NASA air-breathing propulsion CFD codes and boundary layer transition/aeroheating models using X-51 ground/flight test data \& Shuttle flight data

\section{Integrated \\ Systems Research Program}

- X-48B Low Speed Flight Controls Flight Test

- GE Open Rotor Wind Tunnel Test

- HWB/Advanced Tube and Wing System Study Completed

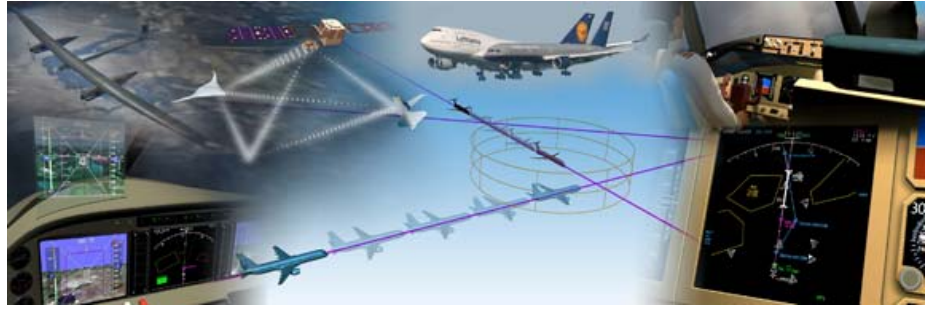

Airspace Systems Program

- Investigate allocation of traffic management functions between human and automation and between ground and the flight deck

- Partner with FAA and industry to develop fuel and noise efficient arrival operations
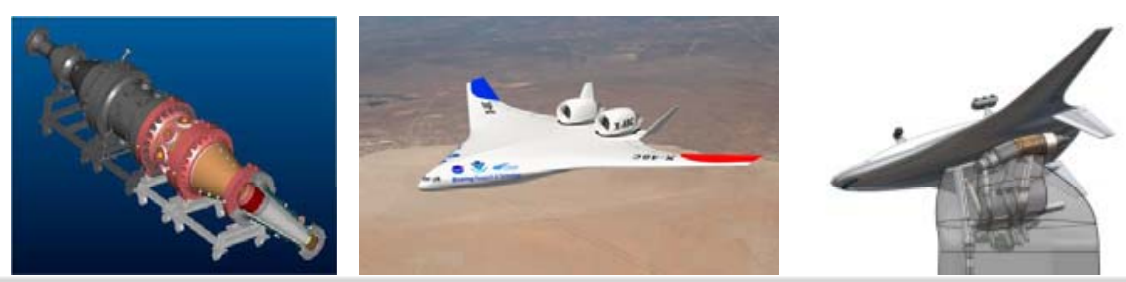

\section{Aviation Safety Program}
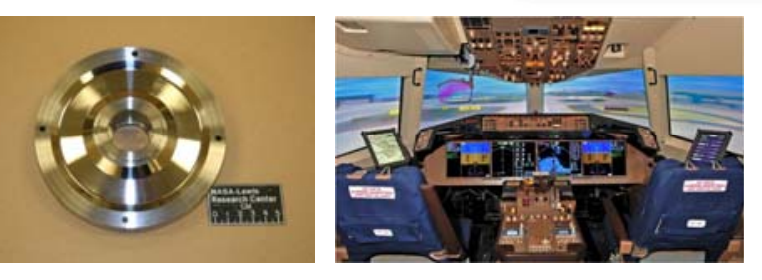

- Enhanced durability of high-temperature engine disks

- Flight deck decision support concepts for terminal area ops

- On-board fault detection for improved health management

Fast, reliable, non-destructive wire crimp test tool
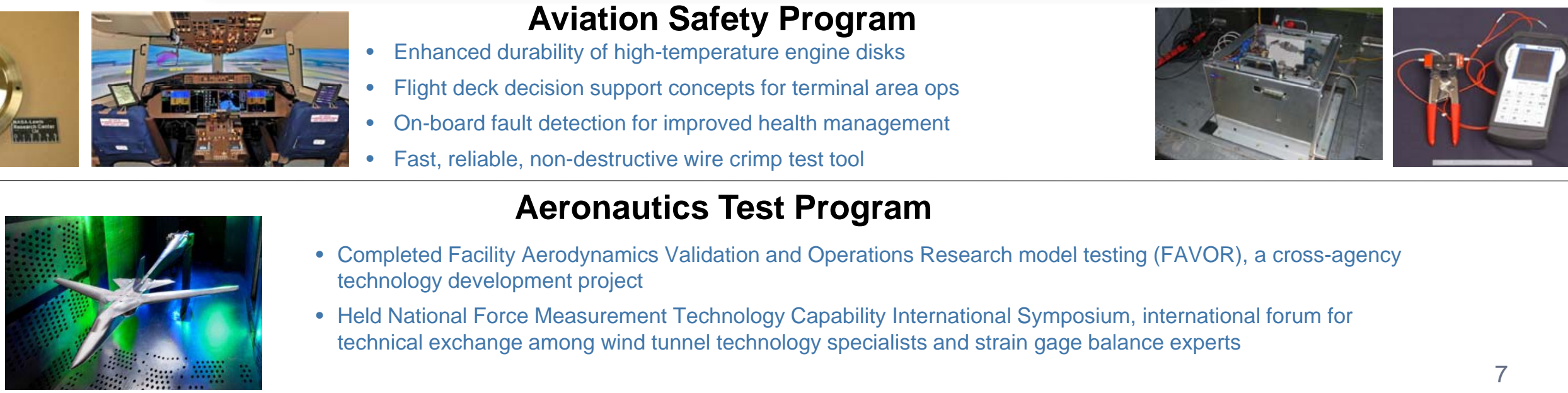

\section{Aeronautics Test Program}

- Completed Facility Aerodynamics Validation and Operations Research model testing (FAVOR), a cross-agency technology development project

- Held National Force Measurement Technology Capability International Symposium, international forum for technical exchange among wind tunnel technology specialists and strain gage balance experts 


\section{FY2011 Budget Highlights}

The 2011 Budget for NASA Aeronautics provides continued emphasis on NASA's contributions to the NextGen and Green Aviation.

- Two new initiatives (\$50M per year) will enhance our contributions to NextGen

- The Unmanned Aircraft System (UAS) integration into the NAS is a five year focused program of systems-level research and demonstration of concepts and technologies that will enable the development and certification of safe, routine operation of unmanned systems in the national airspace.

- The V\&V of Aviation Flight Critical Systems initiative will enable research of $\mathrm{V} \& \mathrm{~V}$ methodologies and concepts to test, validate, and certify complex hardware and software systems that will perform reliably, securely, and safely as intended.

- Augmenting research to mitigate environmental impacts with $\$ 20 \mathrm{M} / \mathrm{yr}$
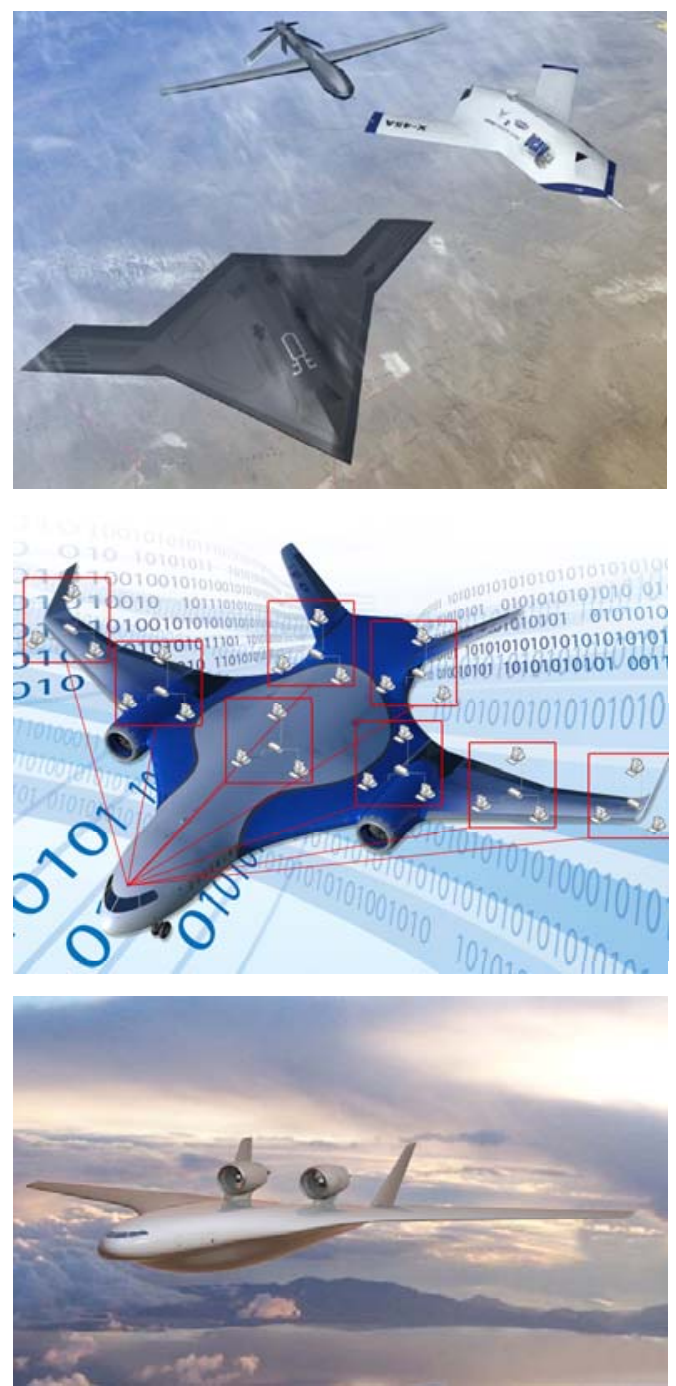


\section{Collaboration with External Partners}
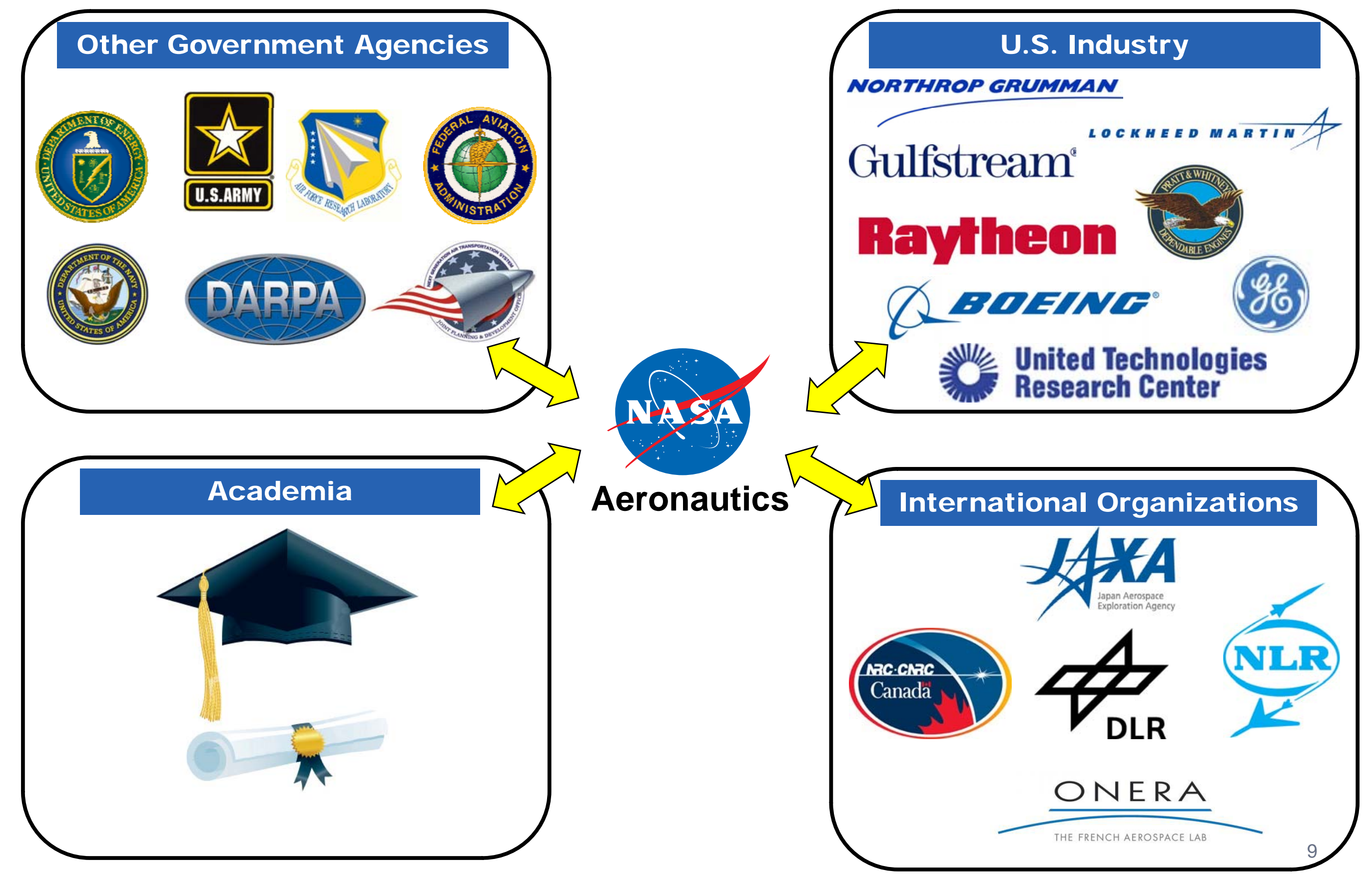
Naga 